\title{
Thrombolysis Induction
}

National Cancer Institute

\section{Source}

National Cancer Institute. Thrombolysis Induction. NCI Thesaurus. Code C40869.

The processes involved in initiation of the complex series of events that result in dissolution of a thrombus (blood clot) and restoration of normal blood flow. 